\title{
Hormonal regulation of chicken intestinal NHE and SGLT-1 activities
}

\author{
MARIA CARMEN DE LA HORRA, MERCEDES CANO, MARIA JOSÉ PERAL, \\ MARIA LUISA CALONGE, AND ANUNCIACIÓN ANA ILUNDÁIN \\ Departamento Fisiología y Biología Animal, Facultad de Farmacia, \\ Universidad de Sevilla, 41012 Sevilla, Spain
}

Received 27 March 2000; accepted in final form 23 October 2000

\begin{abstract}
De La Horra, Maria Carmen, Mercedes Cano, Maria José Peral, Maria Luisa Calonge, and Anunciación Ana Ilundáin. Hormonal regulation of chicken intestinal NHE and SGLT-1 activities. Am J Physiol Regulatory Integrative Comp Physiol 280: R655-R660, 2001.-The effects of aldosterone and arginine vasotocin (AVT) on intestinal $\mathrm{Na}^{+} / \mathrm{H}^{+}$ exchange (NHE) and $\mathrm{Na}^{+}$-sugar cotransport (SGLT-1) activities have been investigated using brush-border membrane vesicles isolated from Hubbard chicken small and large intestines, and they were compared with those induced by either $\mathrm{Na}^{+}$ depletion or dehydration. $\mathrm{Na}^{+}$depletion was induced by feeding the chickens with either a low- or a high- $\mathrm{Na}^{+}$diet for either 0.5 , $1,2,4$, or 8 days. Ileal and colonic NHE2 activity increased with the duration of the $\mathrm{Na}^{+}$depletion, whereas that of intestinal SGLT-1 decreased, reaching a plateau after 2 days of treatment. Three-hour incubation of the intestine with aldosterone produced the same effects on NHE activity as does $\mathrm{Na}^{+}$depletion, without altering SGLT-1 activity. However, 3-h incubation of the intestine with AVT increased intestinal SGLT-1 activity, without affecting intestinal NHE activity. It is concluded that aldosterone regulates apical ileal and colonic NHE2 activity, whereas that of SGLT-1 is regulated by AVT.
\end{abstract}

low- $\mathrm{Na}^{+}$diet; aldosterone; arginine vasotocin; brush-border membrane vesicle; sodium/hydrogen exchange

IN MAMMALS, THE KIDNEY and the large intestine are the major regulators of body electrolyte and water homeostasis. As birds do not have a urinary bladder, the urine is emptied into the cloaca, and retrograde flow carries urine into the coprodeum, the colon (rectum), and cecum. As a result, the epithelia of the lower intestine process the ileal and ureteral outflow. We previously reported that dietary $\mathrm{Na}^{+}$depletion decreased $\mathrm{Na}^{+}$-sugar cotransport (SGLT-1) activity and increased that of apical sodium/hydrogen exchange (NHE) in the chick ileum and colon $(6,7)$. We also showed (6) that 4 days of water deprivation increased the activities of both apical NHE and SGLT-1 in jejunum, ileum, and colon of the chicken. Therefore, $\mathrm{Na}^{+}$ depletion decreased intestinal SGLT-1 activity, whereas it was increased by dehydration. Because both treatments increased plasma aldosterone levels, it was

Address for reprint requests and other correspondence: A. A. Ilundáin, Dept. Fisiología y Biología Animal, Facultad de Farmacia, C) Tramontana s/n, 41012 Sevilla, Spain (E mail: ilundain@cica.es). concluded that aldosterone does not regulate intestinal SGLT-1 (6).

The purpose of the current work was to investigate in brush-border membrane vesicles (BBMV) isolated from chicken small and large intestine the time course of the effects of $\mathrm{Na}^{+}$depletion on intestinal NHE and SGLT-1 activities and the effects of aldosterone and arginine vasotocin (AVT) on those $\mathrm{Na}^{+}$-linked transport systems activities.

\section{MATERIALS AND METHODS}

Solutions. For ${ }^{22} \mathrm{Na}^{+}$uptake experiments, the intravesicular buffer contained (in mM) 140 mannitol, $50 \mathrm{~K}$-gluconate, and 50 Mes-Tris (pH 5.5). The uptake buffer consisted of (in $\mathrm{mM}$ ) 140 mannitol, $50 \mathrm{~K}$-gluconate, 0.045 valinomycin, 0.1 Na-gluconate, tracers of ${ }^{22} \mathrm{Na}^{+}$, and either 50 Mes-Tris $(\mathrm{pH}$ 5.5) or 50 HEPES-Tris ( $\mathrm{pH} 7.5$ ). The stop solution contained (in $\mathrm{mM}$ ) 140 mannitol, $50 \mathrm{~K}$-gluconate, 50 Mes-Tris (pH 5.5), and 0.1 amiloride. The protein concentration per assay tube was $100-150 \mu \mathrm{g} / 100 \mu \mathrm{l}$ of uptake buffer.

$\alpha$-Methyl-glucopyranoside ( $\alpha$-MG) uptake was measured in BBMV loaded with (in mM) 140 mannitol, $50 \mathrm{~K}$-gluconate, $0.1 \mathrm{MgSO}_{4}$, and 50 HEPES-Tris ( $\mathrm{pH} \mathrm{7.5)}$. The extravesicular buffer contained (in mM) 140 mannitol, 50 Na-gluconate, 0.1 $\alpha-\mathrm{MG}, 0.045$ valinomycin, and tracers of $\alpha-\left[\mathrm{D}-{ }^{14} \mathrm{C}\right] \mathrm{MG}$ and 50 HEPES-Tris ( $\mathrm{pH} 7.5$ ), with or without 0.25 phlorizin. The stop solution contained (in mM) 140 mannitol, 50 HEPESTris (pH 7.5), 50 K-gluconate, and 0.25 phlorizin. The protein concentration per assay tube was $100 \mu \mathrm{g} / 100 \mu \mathrm{l}$ of uptake buffer.

The everted small and large intestines were incubated for $3 \mathrm{~h}$ in a solution containing (in $\mathrm{mM}$ ) 90 mannitol, $80 \mathrm{NaCl}, 1$ $\mathrm{CaCl}_{2}, 1 \mathrm{MgCl}_{2}, 3 \mathrm{~K}_{2} \mathrm{HPO}_{4}, 25 \mathrm{HCO}_{3}$ choline (pH 7.4), and the desired hormone, and it was continuously bubbled with $95 \% \mathrm{O}_{2}$ and $5 \% \mathrm{CO}_{2}$. The medium was also supplemented with $10 \mathrm{mM}$ glucose, $100 \mathrm{U} / \mathrm{ml}$ penicillin, and $100 \mu \mathrm{g} / \mathrm{ml}$ streptomycin. The $\mathrm{pH}$ of the solution was controlled throughout the experiment.

Animals and diets. Two groups of Hubbard chickens, 10 wk old, were adapted, before being killed, for either 0.5, 1, 2, 4 , or 8 days to either a high- $\mathrm{NaCl}$ diet or a low-NaCl diet as described (14). The low-NaCl treatment consisted of low$\mathrm{NaCl}$ balanced food and demineralized water containing 1 $\mathrm{mM} \mathrm{CaCl}_{2}$. The high-NaCl treatment consisted of high-NaCl

The costs of publication of this article were defrayed in part by the payment of page charges. The article must therefore be hereby marked "advertisement" in accordance with 18 U.S.C. Section 1734 solely to indicate this fact. 
balanced food and demineralized water containing $1 \mathrm{mM}$ $\mathrm{CaCl}_{2}$ plus $0.5 \% \mathrm{NaCl}(\mathrm{wt} / \mathrm{vol})$.

Another group of chickens was fed a commercial diet for 10 wk. After chickens were killed with an intravenous injection of urethane, the small and large intestines were removed, opened longitudinally, rinsed clean with ice-cold saline solution, and incubated for $3 \mathrm{~h}$ in the absence or presence of either $0.5 \mu \mathrm{M}$ aldosterone or $0.5 \mu \mathrm{M}$ AVT.

Plasma analysis. Blood samples were collected from a wing vein into ice-cold heparinized tubes and centrifuged immediately at $4^{\circ} \mathrm{C}$. Plasma aldosterone was measured by radioimmunoassay by Cerba laboratories (Barcelona, Spain). $\mathrm{Na}^{+}$ and $\mathrm{K}^{+}$were measured by flame photometry and osmolality with an osmometer (Osmometer Gonotec, Osmomat 030). Glucose was measured enzymatically.

Glucose, $\mathrm{Na}^{+}, \mathrm{K}^{+}$, and osmolality of the intestinal content. The animals were killed by intravenous injection of urethane, the tissues were removed, and the content of jejunum, ileum, or colon was emptied into centrifuge tubes. After centrifugation at $5,000 \mathrm{rpm}$ at $4^{\circ} \mathrm{C}$ for $20 \mathrm{~min}$, samples were taken from the supernatant and tested for $\mathrm{Na}^{+}, \mathrm{K}^{+}$, glucose, and osmolality as described above.

$B B M V$ preparation. The small and large intestines were rinsed with ice-cold saline solution and opened longitudinally. The mucose was scraped off with a glass slide, wrapped in aluminum foil, frozen in liquid nitrogen, and kept at $-80^{\circ} \mathrm{C}$ until use.

BBMV were isolated from either jejunum or ileum as described by Peral et al. (12). Briefly, the mucose was thawed in a buffer containing (in mM) 100 mannitol, 2 HEPES-Tris (pH 7.1), 0.2 phenylmethylsulfonyl-fluoride (PMSF), 0.5 DLdithiothreitol, and 0.2 benzamidine, homogenized in a Waring blender (model $32 \mathrm{BL} 80$ ) at high speed for $30 \mathrm{~s}$ and filtered through a Buchner funnel. $\mathrm{MgCl}_{2}$ was added to the homogenate to a final concentration of $10 \mathrm{mM}$. The suspension was stirred for $20 \mathrm{~min}$ and then centrifuged at 3,000 $\mathrm{g}$ for $15 \mathrm{~min}$. The plasma membranes retained in the supernatant were collected by centrifugation at $30,000 \mathrm{~g}$ for $30 \mathrm{~min}$. The resultant pellet was suspended in a $\mathrm{pH} 7.4$ buffer consisting of (in mM) 100 mannitol, 2 HEPES-Tris, and 0.1 $\mathrm{MgSO}_{4}$. This suspension was homogenized with 50 up-down strokes with a glass-Teflon homogenizer, brought up to 35$40 \mathrm{ml}$ with the same buffer, and centrifuged at $30,000 \mathrm{~g}$ for 30 min. The final pellet, containing the purified BBMV, was suspended in the loading buffers as described above. The final suspension was homogenized by passing the suspension through 25- and 28-gauge needles. All the steps were carried out at $4^{\circ} \mathrm{C}$.

BBMV were isolated from the colonic mucose, by the method described by Harig et al. (9), using $\mathrm{Mg}^{2+}$ precipitation instead of $\mathrm{Ca}^{2+}$ precipitation as described in Calonge et al. (3). Briefly, the mucose was defrosted in a solution (14 $\mathrm{ml} / \mathrm{g}$ ) containing (in $\mathrm{mM}$ ) 50 mannitol, 0.2 PMSF, 0.5 DLdithiothreitol, 0.2 benzamidine, and 2 HEPES-Tris, $\mathrm{pH}$ 7.0; homogenized with a Ystral Politron at setting 4 for $90 \mathrm{~s}$, and filtered through a nylon gauze. $\mathrm{MgCl}_{2}$, at a final concentration of $10 \mathrm{mM}$, was added to the homogenate and stirred for $20 \mathrm{~min}$. The suspension was centrifuged at $1,000 \mathrm{~g}$ for 10 min, the resultant supernatant was centrifuged at $39,000 \mathrm{~g}$ for $20 \mathrm{~min}$, and the resultant pellet was suspended in appropriate loading buffers. The suspension was homogenized with 20 up-down strokes with a glass-Teflon dounce homogenizer and centrifuged at 39,000 $\mathrm{g}$ for $30 \mathrm{~min}$. The pellet was resuspended in the loading buffers described above. The isolated apical membranes were made homogenous by passing them through a 25 - and a 26 -gauge needle several times; they were stored in liquid nitrogen until use. All the steps were carried out at $4^{\circ} \mathrm{C}$.

Protein was measured by the method of Lowry et al. (13) using albumin as the standard.

Uptake studies. ${ }^{22} \mathrm{Na}^{+}$or $\alpha$-[D- $\left.{ }^{14} \mathrm{C}\right] \mathrm{MG}$ uptake was measured at $25^{\circ} \mathrm{C}$ by a rapid filtration technique as described (4). Briefly BBMV were left to stand at room temperature $\left(\sim 25^{\circ} \mathrm{C}\right)$ for $10 \mathrm{~min}$. Timed incubations at room temperature were initiated by adding $10 \mu \mathrm{l}$ of suspended membrane vesicles to $90 \mu \mathrm{l}$ of uptake buffer (100-150 $\mu \mathrm{g}$ of protein/100 $\mu \mathrm{l}$ uptake buffer). The composition of the uptake buffers is given above. After designated periods of time, uptake was terminated by the addition of $2.5 \mathrm{ml}$ of an ice-cold stop solution of the same composition as that of the intravesicular buffer. The samples were immediately filtered under vacuum through a $0.45-\mu \mathrm{m}$ pore size Millipore filter prewetted with the stop buffer. Filters were further washed twice with $5 \mathrm{ml}$ of ice-cold stop solution, dissolved in $5 \mathrm{ml}$ of Ready-Protein (Beckman) scintillation fluid, and radioactivity was determined by liquid scintillation spectrometry. Nonspecific isotope binding to the filters was determined separately by adding stop solution to the vesicles before addition of uptake buffer and subtracted from the total radioactivity of each sample. All experiments were done in triplicate.

Materials. ${ }^{22} \mathrm{Na}^{+}$or $\alpha-\left[\mathrm{D}-{ }^{14} \mathrm{C}\right] \mathrm{MG}$ were purchased from Amersham. Valinomycin, AVT, aldosterone, phlorizin, and all the salts used in the current study were obtained from Sigma Chemical. HOE-694 was a gift from Dr. M. Donowitz.

Calculations and statistics. Vertical bars in Figs. 1-5 represent SE; they are absent when they are less than symbol height. Results are expressed as means \pm SE. Statistical significance was evaluated by Dunnett's test.

\section{RESULTS}

Adaptation to a low- $\mathrm{Na}^{+}$diet and plasma and intestinal fluid parameters. Plasma aldosterone levels increased nearly hyperbolically with the duration of the $\mathrm{Na}^{+}$depletion from 13 to $170 \mathrm{pg} / \mathrm{ml}$, with a half-time close to 1 day (Fig. 1). The plasma levels of either

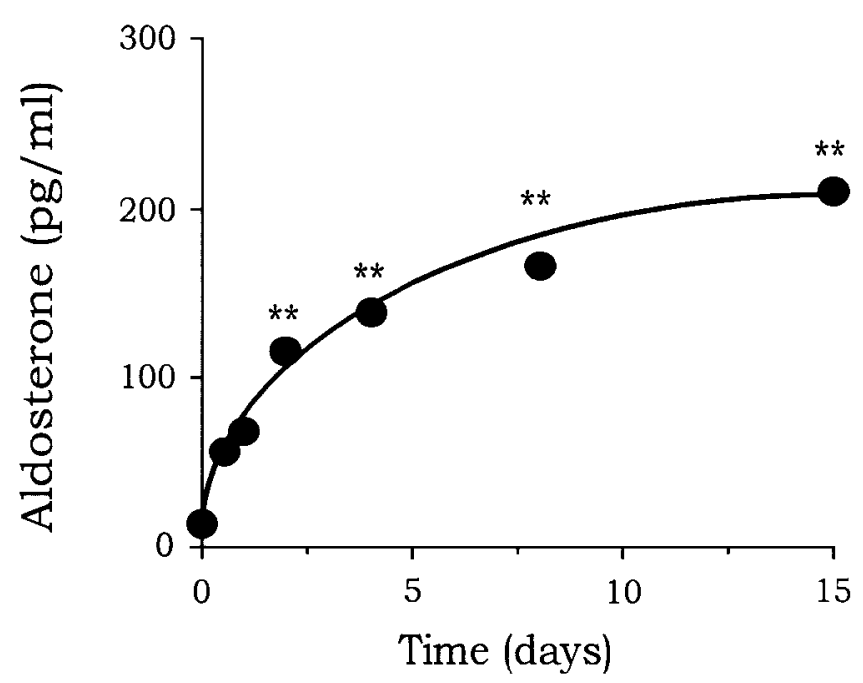

Fig. 1. Plasma aldosterone concentration plotted vs. the duration of $\mathrm{Na}^{+}$depletion. Aldosterone was measured as explained in MATERIALS AND METHODS. Data are the mean values \pm SE of 4 animals. $* * P<$ 0.01 compared with commercial diet (zero time). The data at time 15 days have been taken from a previous report (7). 
sodium or glucose or osmolality were not affected by the treatment (Table 1).

After 12 -h adaptation to a low- $\mathrm{Na}^{+}$diet, the $\mathrm{K}^{+}$ concentration in the luminal fluid of the three intestinal regions was increased (see Table 1). The treatment also increased glucose concentration in the intestinal content, whereas that of $\mathrm{Na}^{+}$was decreased until values were undetectable (see Table 1). Intestinal fluid osmolality did not change in the small intestine, and it was decreased in the colon (see Table 1). Although the food delivery was neither measured nor controlled, it was noted that the animals fed on a low- $\mathrm{Na}^{+}$diet tended to eat less (the amount of food remaining in the containers was always greater than that in those containing high- $\mathrm{Na}^{+}$diet). However, a decrease in food intake would not explain the measured increase in both $\mathrm{K}^{+}$and glucose concentrations in the intestinal content; hence these observations suggest that intestinal transport activity was changed by the treatment.

$\mathrm{Na}^{+}$content in the diet and $\mathrm{Na}^{+}$uptake into BBMV isolated from chick intestine. $\mathrm{Na}^{+}$uptake into chicken intestinal BBMV was measured in the presence and absence of an inwardly directed $\mathrm{pH}$ gradient and under membrane voltage-clamped conditions (equal internal and external potassium concentrations plus valinomycin). The contribution of either NHE2 or NHE3 to total NHE activity was determined using the amiloriderelated drug HOE-694 $(50 \mu \mathrm{M})$, which in rat and rabbit has higher sensitivity to NHE2 $\left(K_{\mathrm{i}}, 5 \mu \mathrm{M}\right)$ than to NHE3 $\left(K_{\mathrm{i}}, 650 \mu \mathrm{M}\right)(5,16)$. Therefore, $50 \mu \mathrm{M}$ HOE-694 will inhibit NHE2 activity and will have no significant effect on NHE3 activity.
The results revealed (Fig. 2) that jejunal NHE activity was not modified by $\mathrm{Na}^{+}$depletion, whereas both ileal and colonic NHE activity increased with the time of the duration of treatment, and the increase was due to increased NHE2 activity. NHE3 activity was not modified.

Time-dependent effect of $\mathrm{Na}^{+}$depletion on SGLT-1 activity in BBMV isolated from chicken intestine. Sugar uptake into intestinal BBMV was measured in the presence of an inwardly directed electrochemical $\mathrm{Na}^{+}$ gradient, with or without phlorizin.

Feeding with a low- $\mathrm{Na}^{+}$diet significantly decreased SGLT-1 activity in jejunum, ileum, and colon (Fig. 3). The downregulation of SGLT-1 activity reached a plateau at 2 days of treatment. Low- $\mathrm{Na}^{+}$diet did not affect the phlorizin-insensitive sugar transport component (data not shown).

Effect of either aldosterone or AVT on SGLT-1 and NHE activities in BBMV isolated from the jejunum, ileum, and colon. BBMV were isolated from jejunum, ileum, and colon after 3-h incubation with or without $0.5 \mu \mathrm{M}$ aldosterone or $0.5 \mu \mathrm{M}$ AVT. Sugar uptake and $\mathrm{Na}^{+}$uptake into BBMV were measured as indicated above.

The results show (Figs. 4 and 5) that aldosterone and AVT affected intestinal $\mathrm{Na}^{+}$-linked transport systems activity differently. Thus aldosterone increased ileal and colonic NHE activity, via an increase in NHE2 activity. Jejunal NHE activity was not modified by aldosterone (data not shown). On the other hand, intestinal NHE activity was not significantly modified by AVT.

Table 1. Plasma and intestinal fluid parameters vs. the duration of $\mathrm{NaCl}$ depletion

\begin{tabular}{|c|c|c|c|c|c|c|}
\hline & \multicolumn{6}{|c|}{ Days } \\
\hline & 0 & 0.5 & 1 & 2 & 4 & 8 \\
\hline & \multicolumn{6}{|c|}{$\mathrm{Na}^{+}, \mathrm{mM}$} \\
\hline Jejunum & $110 \pm 5$ & $72 \pm 6 \dagger$ & $56 \pm 8 \dagger$ & $46 \pm 7 \dagger$ & - & - \\
\hline Ileum & $108 \pm 5$ & $75 \pm 4^{*}$ & $45 \pm 7 \dagger$ & - & - & - \\
\hline Colon & $93 \pm 6$ & - & - & - & - & - \\
\hline \multirow[t]{2}{*}{ Plasma } & $137 \pm 4$ & $130 \pm 3$ & $128 \pm 2$ & $148 \pm 2$ & $135 \pm 3$ & $137 \pm 2$ \\
\hline & \multicolumn{6}{|c|}{$K^{+}, m M$} \\
\hline Jejunum & $16 \pm 1$ & $22 \pm 1$ & $29 \pm 2 \dagger$ & $31 \pm 3 \dagger$ & $26 \pm 2^{*}$ & $26 \pm 2^{*}$ \\
\hline Ileum & $14 \pm 1$ & $22 \pm 1$ & $35 \pm 3 \dagger$ & $35 \pm 3 \dagger$ & $38 \pm 4 \dagger$ & $36 \pm 3 \dagger$ \\
\hline Colon & $30 \pm 4$ & $38 \pm 5$ & $38 \pm 3$ & $39 \pm 6$ & $32 \pm 2$ & $31 \pm 6$ \\
\hline \multirow[t]{2}{*}{ Plasma } & $6.3 \pm 0.1$ & $9.4 \pm 0.7$ & $8.2 \pm 0.3$ & $8.4 \pm 0.3$ & $8.7 \pm 0.4$ & $9 \pm 0.5$ \\
\hline & \multicolumn{6}{|c|}{ Glucose, $m M$} \\
\hline Jejunum & $13 \pm 1$ & $27 \pm 2 \dagger$ & $41 \pm 0.2 \dagger$ & $35 \pm 1 \dagger$ & $41 \pm 1 \dagger$ & $33 \pm 2 \dagger$ \\
\hline Ileum & $7 \pm 0.4$ & $14 \pm 1 \dagger$ & $17 \pm 2 \dagger$ & $14 \pm 1 \dagger$ & $13 \pm 0.5 \dagger$ & $15 \pm 1 \dagger$ \\
\hline Colon & $1.2 \pm 0.1$ & $5.2 \pm 0.6^{*}$ & NM & $4.2 \pm 0.6$ & $6.4 \pm 1 \dagger$ & $7 \pm 1 \dagger$ \\
\hline \multirow[t]{2}{*}{ Plasma } & $13 \pm 0.2$ & NM & $12.8 \pm 0.3$ & $13 \pm 0.3$ & $13 \pm 0.8$ & $14 \pm 1$ \\
\hline & \multicolumn{6}{|c|}{ Osmolality, mosmol/ $\mathrm{KgH}_{2} \mathrm{O}$} \\
\hline Jejunum & $461 \pm 23$ & $480 \pm 14$ & $482 \pm 24$ & $480 \pm 20$ & $426 \pm 14$ & $464 \pm 26$ \\
\hline Ileum & $407 \pm 22$ & $389 \pm 17$ & $400 \pm 14$ & $418 \pm 8$ & $378 \pm 28$ & $394 \pm 2$ \\
\hline Colon & $300 \pm 15$ & $230 \pm 12 \dagger$ & $230 \pm 12 \dagger$ & $220 \pm 12 \dagger$ & $200 \pm 12 \dagger$ & $200 \pm 12 \dagger$ \\
\hline Plasma & $336 \pm 6$ & $354 \pm 28$ & $338 \pm 18$ & $336 \pm 23$ & $308 \pm 9$ & $320 \pm 7$ \\
\hline
\end{tabular}

Values are means $\pm \mathrm{SE}\left(n=4\right.$ animals). Glucose, $\mathrm{Na}^{+}$and $\mathrm{K}^{+}$concentrations, and osmolality have been measured as described in MATERIALS AND METHODS. NM, nonmeasured. - , undetectable. ${ }^{*} P<0.05, \dagger P<0.001$ as compared with high-Na ${ }^{+}$diet (at $d a y 0$ ). 

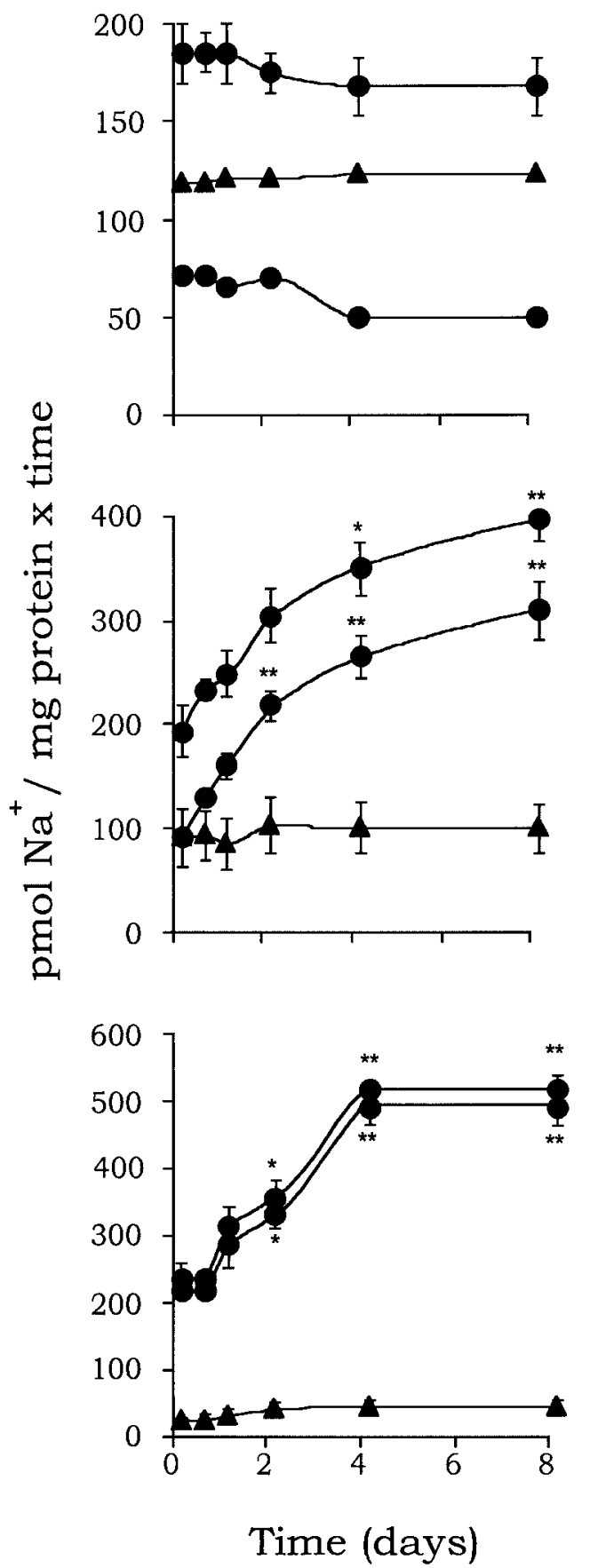

Fig. 2. Adaptation to a low-Na ${ }^{+}$diet and sodium/hydrogen exchange (NHE) activity in brush-border membrane vesicles (BBMV) isolated from chicken intestine. $\mathrm{Na}^{+}$uptake was measured in the presence $\left(5.5_{\mathrm{i}} / 7.5_{\mathrm{o}}\right)$ and absence $\left(5.5_{\mathrm{i}} / 5.5_{\mathrm{o}}\right)$ of a proton gradient, during $1 \mathrm{~min}$ for jejunum (top) and ileum (middle) and $5 \mathrm{~min}$ in colon (bottom; time of peak overshoot values). The composition of the intra- and extravesicular buffers are given in MATERIALS AND METHODS. The concentration of HOE-694 was $50 \mu \mathrm{M}$. When tested, the vesicles were preincubated with the inhibitor for $12 \mathrm{~min}$. NHE activity (1st $\bullet$ ): $\mathrm{Na}^{+}$ uptake measured in the presence of a $\mathrm{pH}$ gradient minus that measured in the absence of a $\mathrm{pH}$ gradient. NHE2 activity (₫): $\mathrm{pH}$ gradient-dependent $\mathrm{Na}^{+}$uptake sensitive to HOE-694. NHE3 activity (2nd •): $\mathrm{pH}$ gradient-dependent $\mathrm{Na}^{+}$uptake insensitive to $\mathrm{HOE}-$ 694. Data are mean values \pm SE of 4 separate membrane vesicle preparations. $* P<0.05, * * P<0.001$, compared with high- $\mathrm{Na}^{+}$diet (zero time).

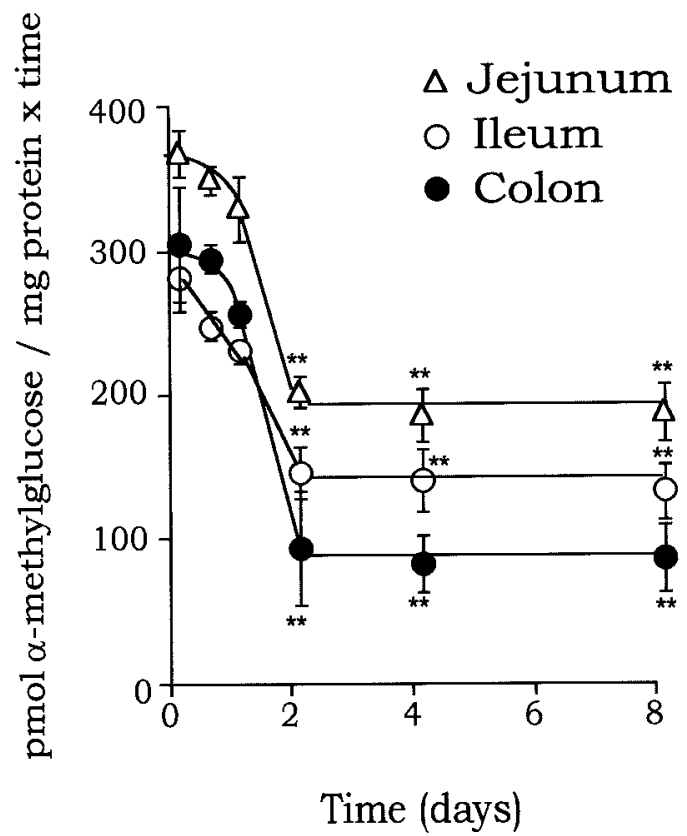

Fig. 3. Adaptation to a low- $\mathrm{Na}^{+}$diet and $\mathrm{Na}^{+}$-sugar cotransport activity in BBMV isolated from chicken intestine. $\alpha$-Methyl-glucopyranoside $(\alpha-M G)$ uptake into BBMV was measured in the presence of an inwardly directed electrochemical $\mathrm{Na}^{+}$gradient, with or without $0.25 \mathrm{mM}$ phlorizin, over $30 \mathrm{~s}$ for jejunum and ileum and $1 \mathrm{~min}$ for the colon (time of the peak overshoot values). Electrical membrane potential was created by an outwardly directed $\mathrm{K}^{+}$gradient in the presence of valinomycin. An inside directed $\mathrm{Na}^{+}$gradient was created by the addition of $50 \mathrm{mM} \mathrm{Na}^{+}$to the extravesicular buffer. The intravesicular buffer was made nominally $\mathrm{Na}^{+}$free. The data represent the $\mathrm{Na}^{+}$-dependent, phlorizin-sensitive sugar uptake (SGLT-1 activity), which is the total sugar uptake minus that measured in the presence of phlorizin. Data are mean values $\pm \mathrm{SE}$ of 4 separate membrane vesicle preparations. ${ }^{* *} P<0.001$ compared with high$\mathrm{Na}^{+}$diet (zero time)

Small and large intestinal SGLT-1 activity was not modified by the in vitro exposure of the tissues to aldosterone (Fig. 5), but it was stimulated by AVT.

\section{DISCUSSION}

The current results show for the first time that AVT stimulates intestinal SGLT-1 activity and corroborate our previous view (6) that aldosterone does not mediate the effects of $\mathrm{Na}^{+}$depletion on intestinal SGLT-1 activity.

The following observations suggest that aldosterone regulates ileal and colonic NHE2 activity, but it does not mediate the decrease in intestinal SGLT-1 activity induced by $\mathrm{Na}^{+}$depletion: 1) incubation of the intestine with aldosterone increased ileal and colonic NHE2 activity as it does $\mathrm{Na}^{+}$depletion; 2) SGLT-1 activity was decreased by $\mathrm{Na}^{+}$depletion but it was not affected by aldosterone; and 3) the time course of the effect of $\mathrm{Na}^{+}$depletion on plasma aldosterone levels is similar to that on NHE2 activity, but not to that on SGLT-1 activity.

We (6) have suggested that, because $\mathrm{Na}^{+}$depletion and dehydration increased plasma aldosterone levels and produced opposite effects on SGLT-1 activity, al- 


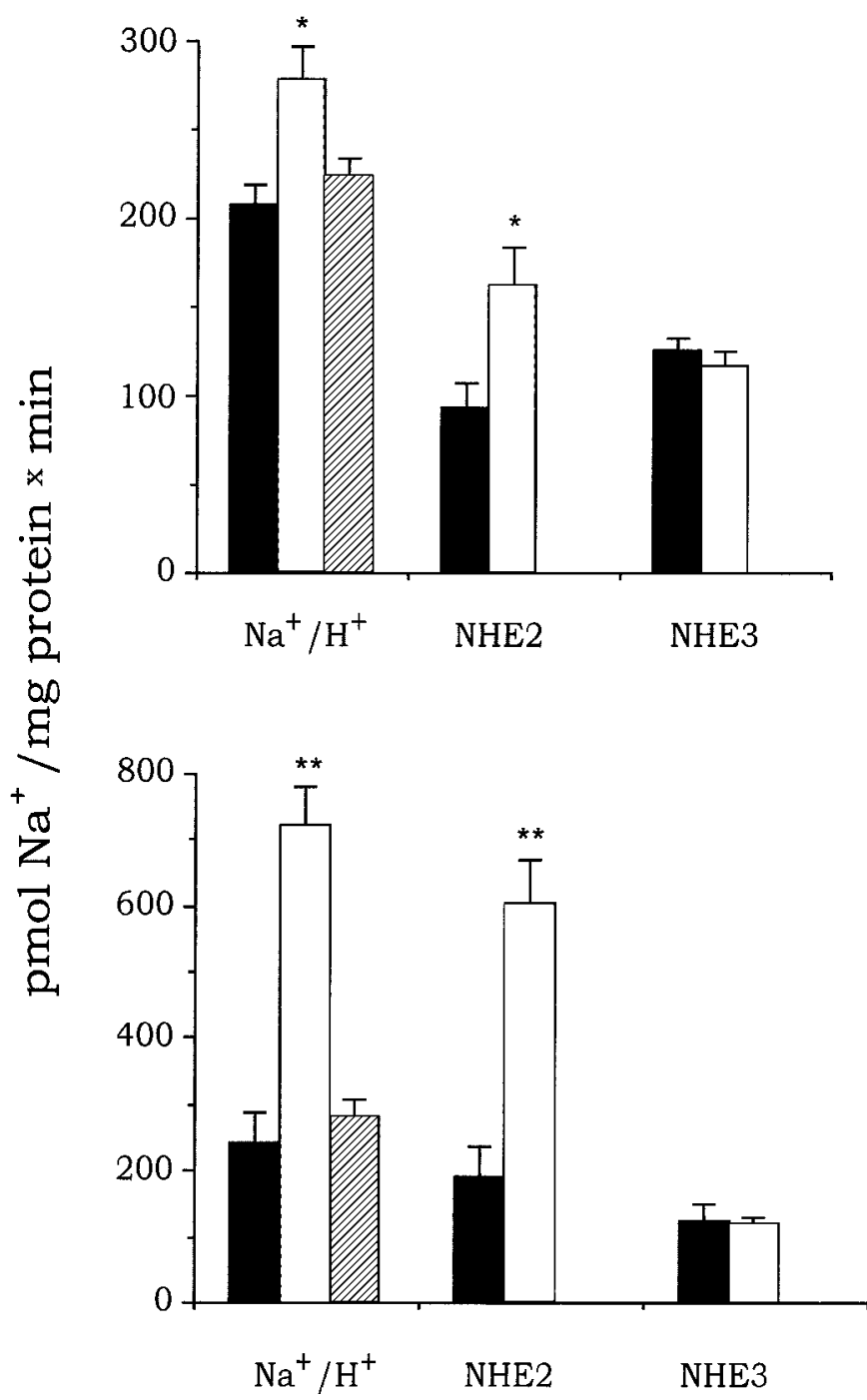

Fig. 4. Effect of either aldosterone (open bars) or arginine vasotocin (AVT; hatched bars) on NHE activity in BBMV isolated from chicken intestine. The ileum (top) and colon (bottom) were incubated in the absence (control; solid bars) and presence of either $0.5 \mu \mathrm{M}$ aldosterone or $0.5 \mu \mathrm{M}$ AVT for $3 \mathrm{~h}$, and BBMV were prepared thereafter. Other details as in Fig. 2. Data are mean values \pm SE of 3 separate membrane vesicle preparations. ${ }^{*} P<0.05, * * P<0.001$ compared with tissues not exposed to hormones.

dosterone does not regulate intestinal SGLT-1. As plasma AVT levels are increased by dehydration (1) and decreased by $\mathrm{Na}^{+}$depletion (2), it was concluded (6) that AVT could be the regulator of intestinal SGLT-1. The current results corroborate this hypothesis, because the incubation of the intestine with AVT increased small and large intestinal SGLT-1 activity.

In our previous study (6) we also suggested that AVT regulates jejunal NHE activity because it was not affected by $\mathrm{Na}^{+}$depletion, but it was increased by dehydration. However, the current results show that neither aldosterone nor AVT significantly affected jejunal NHE activity. These results do not agree with previous reports showing that AVT inhibits NHE3 activity in Madin-Darby canine kidney cells transfected with NHE3 (10).
It could be concluded that, in the chick, 1) apical NHE2 activity in ileum and colon is regulated by aldosterone and 2) small and large intestinal SGLT-1 activity is regulated by AVT. The current results, however, do not provide any clue to explain the increase in jejunal NHE activity induced by dehydration. It could be another hormonal factor. The decrease in intestinal SGLT-1 activity induced by $\mathrm{Na}^{+}$depletion could be due either to a decrease in AVT secretion (2) or to the effect of $\mathrm{Na}^{+}$content in the intestinal lumen on the expression of the SGLT-1. Thus $\mathrm{Na}^{+}$depletion reduced $\mathrm{Na}^{+}$ concentration in the intestinal content until values were undetectable, and this decrease was accompanied by an increase in glucose concentration in the intestinal content. Further investigation is required to characterize the molecular mechanisms underlying the changes in activity of the transporters under study and to determine the link between $\mathrm{Na}^{+}$depletion and intestinal sugar transport activity.

A collateral observation of the current study is that adaptation to a low- $\mathrm{Na}^{+}$diet increased the $\mathrm{K}^{+}$concentration in the luminal fluid of the three intestinal regions, indicating that the treatment stimulated intestinal potassium secretion, which agrees with previous observations in rat colon $(8,15)$.

\section{Perspectives}

The current results agree with the idea that the physiological role of the large intestinal amilorideinhibitable $\mathrm{Na}^{+}$absorption is to conserve $\mathrm{NaCl}$ and that of organic solute- $\mathrm{Na}^{+}$cotransport is to conserve water (14) and suggest that the small intestine could also contribute to these homeostatic functions. Under $\mathrm{Na}^{+}$depletion, both the extracellular fluid volume and

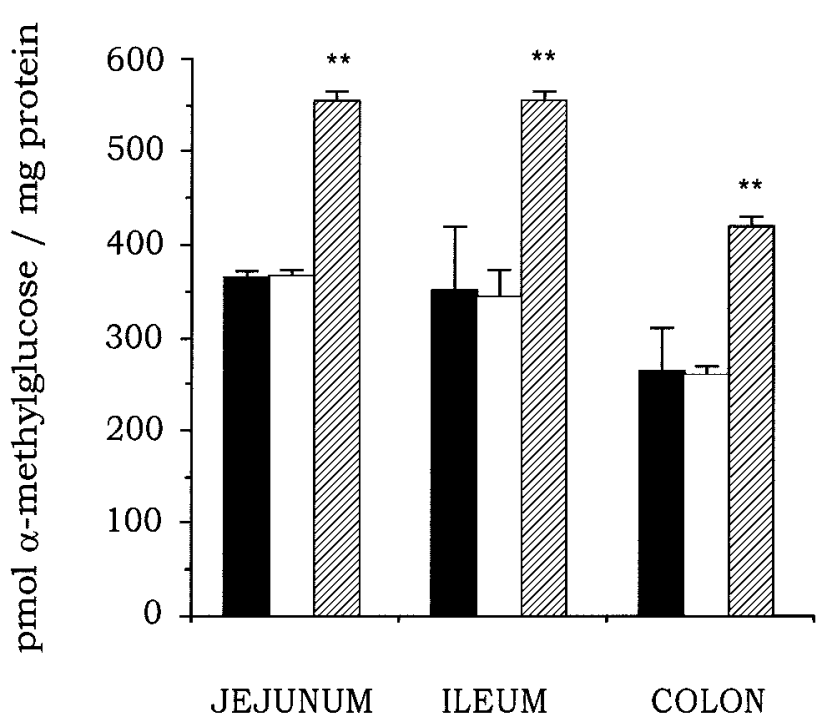

Fig. 5. Effect of either aldosterone (open bars) or AVT (hatched bars) on SGLT-1 activity in BBMV isolated from chicken intestine. The jejunum, ileum and colon were incubated in the absence (control; solid bars) and presence of either $0.5 \mu \mathrm{M}$ aldosterone or $0.5 \mu \mathrm{M}$ AVT for $3 \mathrm{~h}$, and BBMV were prepared thereafter. Other details as in Fig. 3 . Data are mean values $\pm \mathrm{SE}$ of 3 separate membrane vesicle preparations. ${ }^{* *} P<0.001$ compared with tissues not exposed to hormones. 
osmolality fall (11). Regulation of extracellular fluid volume requires $\mathrm{Na}^{+}$and water retention, and osmoregulation demands water excretion in a diluted urine. The increase in $\mathrm{Na}^{+} / \mathrm{H}^{+}$exchange activity and the decrease in $\mathrm{Na}^{+}$-sugar cotransport activity, induced by the low- $\mathrm{Na}^{+}$diet, will help to conserve $\mathrm{Na}^{+}$and to excrete water, respectively. This will be achieved by increasing the plasma levels of aldosterone, which increases $\mathrm{Na}^{+} / \mathrm{H}^{+}$exchange activity, and by decreasing those of AVT, which would reduce SGLT-1 activity. On the other hand, the dehydration-induced increase in both $\mathrm{Na}^{+} / \mathrm{H}^{+}$exchange activity and $\mathrm{Na}^{+}$-dependent sugar transport will help to conserve both $\mathrm{Na}^{+}$and water, and, therefore, to maintain both extracellular fluid volume and osmolality within acceptable limits. From a physiological point of view, it is an advantage that the two $\mathrm{Na}^{+}$-linked transport systems are regulated by a different hormone, which allows different regulation of each transporter according to the homeostatic demands of the organism. The potential physiological contribution of large intestinal active organic solute cotransport could be either to prevent the loss of sugar in the feces or to facilitate it according to the homeostatic needs of the animal.

We thank F. Frieras for technical help.

This work was supported by a grant from the Spanish Dirección General de Investigación Científica y Técnica PM99-0121.

\section{REFERENCES}

1. Arnason SS, Rice GE, Chadwick A, and Skadhauge E. Plasma levels of arginine, vasotocin, prolactin, aldosterone and corticosterone during prolonged dehydration in the domestic fowl: effect of dietary NaCl. J Comp Physiol [A] 156: 383-397, 1986.

2. Arnason SS and Skadhauge E. Steady-state sodium absorption and chloride secretion of colon and coprodeum, and plasma levels of osmoregulatory hormones in hens in relation to sodium intake. J Comp Physiol [A] 161: 1-14, 1991.

3. Calonge ML, De la Horra MC, and Ilundáin AA. $\mathrm{Na}^{+}-\mathrm{H}^{+}$ exchange and intracellular $\mathrm{pH}$ regulation in colonocytes from the chick. Biochim Biophys Acta 1325: 263-271, 1997.

4. Cano M, Vázquez CM, and Ilundáin A. Chloride transport in brush-border membrane vesicles from chick jejunum. Pflügers Arch 425: 395-400, 1993.
5. Counillon L, Scholz W, Lang HJ, and Pouyssegur L. Pharmacological characterization of the stably transfected $\mathrm{Na}^{+}-\mathrm{H}^{+}$ isoforms using amiloride analogs and a new inhibitor exhibiting anti-ischemic properties. Mol Pharmacol 44: 1041-1045, 1993.

6. De la Horra MC, Calonge ML, and Ilundáin AA. Effect of dehydration on apical $\mathrm{Na}^{+} / \mathrm{H}^{+}$exchange activity and $\mathrm{Na}^{+}$-dependent sugar transport in brush-border membrane vesicles isolated from chick intestine. Pflügers Arch 436: 112-116, 1998.

7. Donowitz M, De la Horra MC, Calonge ML, Wood IS, Dyer J, Gribble SM, Sanchez F, Tse CM, Shirazi-Beechey SP, and Ilundáin AA. In birds NHE2 is the major brush-border $\mathrm{Na} / \mathrm{H}$ exchanger in the colon and is increased by a low-NaCl diet. Am J Physiol Regulatory Integrative Comp Physiol 274: R1659R1669, 1998.

8. Foster ES, Hayslett JP, and Binder HJ. Mechanism of active potassium absorption and secretion in the rat colon. $A m J$ Physiol Gastrointest Liver Physiol 246: G611-G617, 1984.

9. Harig JM, Dudeja PK, Knaup SM, Shoshara J, Ramaswamy $\mathbf{K}$, and Brasitus TA. Apical plasma membrane vesicles formed from organ donor colon demonstrate $\mathrm{Na}^{+}$and $\mathrm{H}^{+}$conductances and $\mathrm{Na}^{+}-\mathrm{H}^{+}$exchange. Biochem Biophys Res Commun 167: 438-443, 1990.

10. Helmle-Kolb C, Di Sole F, Forgo J, Hilfiker H, Tse CM, Casavola V, Donowitz M, and Murer $\mathbf{H}$. Regulation of the transfected $\mathrm{Na}^{+}-\mathrm{H}^{+}$exchanger NHE3 in MDCK cells by vasotocin. Pflügers Arch 434: 123-131, 1997.

11. Hladky SB and Rink TJ. Control of extracellular fluid volume, blood volume, and the intake and excretion of sodium. In: Body Fluid and Kidney Physiology, edited by Hobsley M, Saunders KB, and Fitzsimons JT. London: Edward Arnold, 1986, p 159178.

12. Peral MJ, Cano M, and Ilundáin A. $\mathrm{K}^{+}-\mathrm{H}^{+}$exchange activity in brush-border membrane vesicles isolated from chick small intestine. Eur J Biochem 231: 682-686, 1995.

13. Lowry OH, Rosebrough NJ, Farr AL, and Randall RJ. Protein measurement with the Folin phenol reagent. $J$ Biol Chem 193: 265-275, 1951.

14. Skadhauge E, Thomas DH, Chadwick A, and Jallageas $\mathbf{M}$. Time course of adaptation to low and high $\mathrm{NaCl}$ diets in the domestic fowl. Effects on electrolyte excretion and on plasma hormone levels (aldosterone, corticosterone and prolactin). Pflügers Arch 396: 310-307, 1983.

15. Sweiry JH and Binder HJ. Characterization of aldosteroneinduced potassium secretion in rat distal colon. J Clin Invest 83: $844-851,1989$

16. Wormmeester L, Kokke FT, Kambadur R, Tse CM, Yun CHC, Bowser J, Ko W, Cohen ME, and Donowitz M. Quantitation of rabbit ileal brush border $\mathrm{Na} / \mathrm{H}$ exchange activity in up and down regulation of intestinal $\mathrm{Na}$ absorption (Abstract). Gastroenterology 110: A379, 1996. 